\title{
THE TREATMENT OF SHORTWAVE RADIATION AND OPEN WATER IN LARGE-SCALE MODELS OF SEA-ICE DECAY
}

\author{
by
}

Donald K. Perovich

(U.S. Army Cold Regions Research and Engineering Laboratory, 72 Lyme Road, Hanover, NH 03755, U.S.A.)

and

Gary A. Maykut

(Department of Atmospheric Sciences, University of Washington, Seattle, WA 98195, U.S.A.)

\section{ABSTRACT}

Sea ice covering the polar oceans is only a thin veneer whose areal extent can undergo large and rapid variations in response to relatively small changes in thermal forcing. Positive feedback between variations in ice extent and global albedo has the potential to amplify small changes in climate. Particularly difficult to model is the summer decay and retreat of the ice pack which is strongly influenced by shortwave radiation entering the upper ocean through leads $\left(I_{\mathrm{w}}\right)$. Most models assume that all of this energy is expended in lateral melting at floe edges. In reality, only a portion of $I_{\mathrm{w}}$ contributes directly to lateral melting, with the remainder going to bottom ablation and warming of the water. This partitioning of $I_{\mathrm{w}}$ affects not only the magnitude, but also the character of the predicted ice decay, reducing the change in ice concentration and enhancing the thinning of the ice and the storage of heat in the water. In this paper we present an analytical model which includes many of these processes and is stable regardless of time step, making it suitable for use in climate simulations.

\section{INTRODUCTION}

It has long been realized that the positive albedo feedback associated with variations in sea-ice extent may help to amplify small changes in climatic forcing. Because of this, sea-ice extent has played a key role in many theories of climate and models of climatic change. We have begun to realize, however, that predictions made by simple, highly parameterized models provide only limited insight into the relationship between sea ice and climate, partly because of strong coupling between the ice, ocean and atmosphere and partly because of coupling between dynamic and thermodynamic processes in the ice (Thorndike and others, 1975). A more promising approach, made possible by improving computer capabilities, is the utilization of long-term, coupled GCM type simulations. Even here, there are still serious questions as to the level of physics needed to obtain good predictions of ice extent.

Particularly troublesome is the decay and retreat of the ice pack during the summer. In the seasonal sea-ice zone of the Arctic, where up to $2 \mathrm{~m}$ of ice can form during the winter, surface ablation during the summer generally does not exceed $1 \mathrm{~m}$. Complete disappearance of this ice is the result of solar radiation entering the ocean through leads, which produces additional melting on the edges and bottoms of the floes. A similar situation appears to exist in the Southern Ocean. Gordon (1981) estimates that no more than half the energy necessary to remove the seasonal ice cover could be derived from the relatively warm water below the pycnocline. Since surface melting is negligible (Andreas and
Ackley, 1982), the remainder must come from shortwave raditaion absorbed in the upper ocean, either through leads in the ice pack or near the ice edge. Thus summer ice extent is intimately related to ice dynamics and processess occurring in areas of open water within the pack.

The importance of leads in the decay and retreat of the ice pack was first recognized by Zubov (1945) who proposed a simple model based on the positive feedback between energy input to the water and lateral melting on floe edges. The basic assumption of the model was that the solar radiation deposited in leads $\left(I_{\mathrm{w}}\right)$ was totally and immediately used for lateral melting. This produces an exponential increase in the area of open water with time:

$$
A_{\mathrm{w}}=A_{\mathrm{w} 0} \mathrm{e}^{\mathrm{e}_{\mathrm{w}} t / H}
$$

where $A_{\mathrm{w}}$ is the fractional area of open water, $A_{\mathrm{wo}}$ is the initial lead fraction, $t$ is time, $\xi_{\mathrm{w}}=\left(1-\alpha_{\mathrm{w}}\right) F_{\mathrm{r}} /\left(\rho_{\mathrm{i}} L_{\mathrm{f}}\right), \alpha_{\mathrm{w}}$ is the albedo of water, $F_{\mathrm{r}}$ is the incident shortwave irradiance, $H$ is ice thickness, $\rho_{\mathrm{i}}$ is the density of ice, and $L_{\mathrm{f}}$ is the latent heat of fusion of ice.

The Zubov model was subsequently modified by Langleben (1972) to take into account thinning of the ice. Assuming that net longwave losses are balanced by turbulent heat gains and that the net solar radiation goes entirely to surface melting, Langleben obtained the following expression for ice thickness:

$$
H=H_{0}-\xi_{\mathrm{i}} t
$$

where $H_{0}$ is the initial ice thickness at $t=0, \xi_{\mathrm{i}}=$ $\left(1-\alpha_{\mathrm{i}}\right) F_{\mathrm{r}} /\left(\rho_{\mathrm{i}} L_{\mathrm{f}}\right)$ and $\alpha_{\mathrm{i}}$ is the ice albedo. Thinning of the ice results in a modification to the previous expression for $A_{\mathrm{w}}(t):$

$$
A_{\mathrm{w}}=A_{\mathrm{w} 0}\left(1-\xi_{\mathrm{i}} t / H\right)^{-\mu}
$$

where $\mu=\xi_{\mathrm{w}} / \xi_{\mathrm{i}}$. This model was used successfully to predict the disappearance of ice from bays and fiords in the Canadian archipelago. However, when applied under central Arctic conditions, Equations (2)-(3) forecast a much larger reduction in ice concentration and thickness than is actually observed.

Both the Zubov and the Langleben formulations suffer from the assumption that all of $I_{\mathrm{w}}$ is directly used for lateral melting, leading to an unrealistic decrease in ice concentration. In a series of experimental and theoretical studies of energy transport in individual leads, Maykut and Perovich (1987) found that typically less than $25 \%$ of $I_{\mathrm{W}}$ goes to lateral melting, the remainder being expended in melting at the underside of the ice, in warming of the upper ocean, and in energy losses to the atmosphere. To describe this situation they formulated a numerical model (hereafter referred to as the MP model) where: (1) a 
portion of $F_{\mathrm{r}}$ incident on the lead was transmitted to the underlying ocean, (2) lateral melt rates were governed by lead temperature, (3) $F_{\mathrm{r}}$ was allowed to penetrate and warm the interior of the ice, (4) bottom ablation was related to the amount of solar heat accumulated in the underlying water $(Q)$, and (5) longwave and turbulent heat exchange over the ice and lead were taken into account. Results from the MP model suggest a somewhat different melt progression than predicted by the Zubov/Langleben approach. Unfortunately its numerical complexity makes it undesirable for climate modeling. What we would like to have is a solution which maintains the essential physics of the MP model, but is computationally simpler.

\section{ENHANCED ANALYTIC SOLUTION (EA)}

As a first step toward this goal, we modified the MP assumptions to allow analytic expressions for $H(t), A(t)$, and $Q(t)$ to be derived. Like the MP treatment there is a thickness-dependent partitioning of $I_{\mathrm{w}}$ between lateral melting and heat accumulation in the water. This partitioning reduces the overestimation of lateral melting inherent in the Zubov/Langleben treatment and produces a more realistic reduction in ice concentration and thickness during the melt season. We assume that only energy absorbed between the surface of the lead and a depth equal to the ice thickness contributes to lateral ablation. For $H>0.1 \mathrm{~m}$, Perovich (1983) found that the fraction of $F_{\mathrm{r}}$ absorbed between the surface and a depth $\mathrm{z}$ can be closely approximated by:

$$
\left(1-\alpha_{\mathrm{w}}\right)\left(1-i_{\mathrm{w}}\right)=a_{1}+a_{2} \ln (z)
$$

where $i_{\mathrm{w}}$ is the fraction of the net shortwave absorbed below the bottom of the ice, $z$ has units of meters, $a_{1}=0.5676, a_{2}=0.1046$ for clear skies and $a_{1}=0.3938$ and $a_{2}=0.1208$ for cloudy skies. The energy transmitted through the bottom of the lead, $i_{\mathrm{w}}\left(1-\alpha_{\mathrm{w}}\right) F_{\mathrm{r}}$, is stored in the water column and subsequently lost by melting on the underside of the ice.

In contrast to Langleben we do not assume that all of the net shortwave radiation entering the ice goes to surface melting. Since sea ice is translucent rather than opaque, part of $\left(1-\alpha_{\mathrm{i}}\right) F_{\mathrm{r}}$ is stored as latent heat in the brine pockets or transmitted to the ocean. Assuming the ice to be opaque results in a serious overestimation of the amount of surface melting. Unless the ice is very thin, the amount of energy actually transmitted through the ice is small and, for simplicity, we will assume that $\left(1-\alpha_{\mathrm{i}}\right) F_{\mathrm{r}}$ is partitioned solely between surface melting and warming of the ice. Following the arguments of Grenfell and Maykut (1977), we treat the ice as a two-layer system consisting of: (i) an active surface layer (about $0.1 \mathrm{~m}$ in thickness) where all of the energy absorbed in the layer goes to surface melting, and (ii) an underlying homogeneous layer which acts as a reservoir for the remaining energy. If we define $i_{0}$ to be the fraction of the net shortwave transmitted through the surface layer, then the amount of shortwave energy available for surface melting is $\left(1-\alpha_{\mathrm{i}}\right)\left(1-i_{0}\right) F_{\mathrm{r}}$ and the amount for warming the ice is $\left(1-\alpha_{\mathrm{i}}\right) i_{0} F_{\mathrm{r}}$. Grenfell and Maykut (1977) found that $i_{0}$ depends on ice type and the spectral distribution of $F_{\mathrm{r}}$, with values under cloudy and clear skies of 0.35 and 0.18 for white ice and 0.63 and 0.43 for saturated blue ice.

The effect of $\left(1-\alpha_{\mathrm{i}}\right) i_{0} F_{\mathrm{r}}$ is to decrease the amount of energy needed to melt the ice during subsequent time steps, i.e. it changes the latent heat of fusion $\left(L_{\mathrm{f}}\right)$. In sea ice:

$$
L_{\mathrm{f}}=\left(1-v_{\mathrm{b}}\right) L_{0}
$$

where $v_{b}$ is the fractional brine volume of the ice and $L_{0}=0.3335 \mathrm{MJ} \mathrm{kg}^{-1}$ is the latent heat of fusion for pure ice. The change in the average brine volume of the underlying layer is thus:

$$
\mathrm{d} v_{\mathrm{b}} / \mathrm{d} t=i_{0}\left(1-\alpha_{\mathrm{i}}\right) F_{\mathrm{r}} /\left(\rho_{\mathrm{i}} L_{0} H\right)
$$

from which is follows that:

$$
L_{\mathrm{f}}(t)=L_{\mathrm{fo}}-i_{0}\left(1-\alpha_{\mathrm{i}}\right) F_{\mathrm{r}} t /\left(\rho_{\mathrm{i}} H\right)
$$

where $L_{\mathrm{fo}}$ is the initial brine volume. Typical values of $L_{\mathrm{f} 0}$ at the onset of melting are $0.3 \mathrm{MJ} \mathrm{kg}^{-1}$ in multi-year ice and $0.27 \mathrm{MJ} \mathrm{kg}^{-1}$ in first-year ice.

Zubov and Langleben implicitly assumed that the turbulent fluxes and the net longwave radiation flux at the surface roughly balance one another and can be neglected. This turns out to be a good assumption in the near-shore portions of the Arctic, but a poor assumption away from the effects of the land. In simulations using central Arctic summertime conditions Maykut and Perovich (1987) found that, while the sum of the turbulent fluxes was indeed quite small, there were substantial longwave losses which could not be neglected. To estimate incoming longwave radiation $\left(F_{\mathrm{L}}\right)$ we use a parameterization suggested by Maykut and Church (1973)

$$
F_{\mathrm{L}}=\left(0.7855+0.2232 C^{2.75}\right) \sigma T_{\mathrm{a}}^{4},
$$

where $C$ is the fractional cloud cover $(0-1), T_{a}$ is the air temperature and $\sigma=5.67 \times 10^{-8}\left(\mathrm{~W}^{\circ} \mathrm{C}^{-4} \mathrm{~m}^{-2}\right)$ is the Steffan-Boltzmann constant; outgoing longwave radiation is equal to $\varepsilon \sigma T_{S}^{4}$, where $\varepsilon$ is the emissivity and $T_{S}$ is the surface temperature. Under typical summer conditions, the net longwave loss is about $29 \mathrm{~W} \mathrm{~m}^{-2}$ over the ice $\left(F_{\mathrm{Li}}\right)$ and about $24 \mathrm{~W} \mathrm{~m}^{-2}$ over a lead $\left(F_{\mathrm{Lw}}\right)$ where $T_{\mathrm{S}}=-1.8^{\circ} \mathrm{Ci}$.

Probably the most uncertain part of the simulations described below is in the treatment of the shortwave energy
absorbed beneath the ice. It might appear reasonable to return all of this energy immediately to the ice. There is, however, increasing evidence to suggest that this does not happen. Figure 1 shows time-dependent changes in the heat content of the mixed layer beneath a region of dynamically active, first-year ice north of Prince Patrick Island. Ice concentration was roughly $80 \%$ during the observation period. Despite evidence of vigorous vertical mixing, there was a substantial heat build-up suggesting that nonmechanical factors also affect the rate at which heat is lost from the water. Primary among these is a thin, laminar sub-layer which develops in the boundary layer at the bottom of melting sea ice (McPhee and others, 1987) and which strongly limits vertical heat transport to the ice. Ideally we would like to express the rate of heat loss from the water column to the ice $\left(F_{\mathrm{w}}\right)$ as a function of temperature and velocity differences between the ice and the underlying water. Treatment of ice-ocean dynamics is, however, beyond the scope of this paper and we will

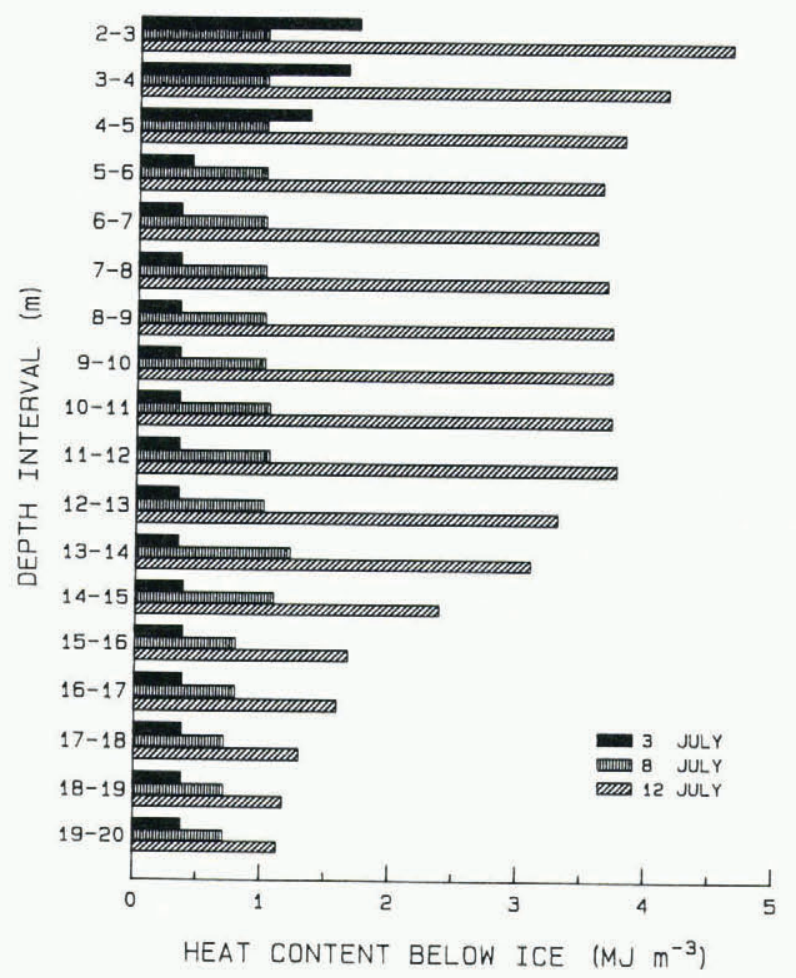

Fig. 1. Heat content of the upper $20 \mathrm{~m}$ of the water column observed in active ice off the north shore of Prince Patrick Island, Canadian archipelago. 
instead assume that the heat content of the mixed layer $(Q)$ is proportional to the ice-water temperature gradient and therefore to $F_{\mathrm{w}}$. Further, to maintain the analytical nature of the solution, we will assume that $F_{\mathrm{w}}$ is constant during a particular solution period, but that it can change between time steps in response to changes in $Q$.

The governing equation for ice thickness is thus

$$
\rho_{\mathrm{i}} L_{\mathrm{f}}(\mathrm{d} H / \mathrm{d} t)=-\left(1-\alpha_{\mathrm{i}}\right)\left(1-i_{0}\right) F_{\mathrm{r}}-F_{\mathrm{w}}-F_{\mathrm{Li}}-F_{\mathrm{t}},
$$

where $F_{\mathrm{ti}}$ and $F_{\mathrm{tw}}$ are the net turbulent fluxes over the ice and lead, respectively.

Integration yields

$$
H(t)=H_{0}-B t
$$

where $B=\left(1-i_{0}\right) \xi_{\mathrm{i}}+\left(F_{\mathrm{w}}+F_{\mathrm{Li}}+F_{\mathrm{ti}}\right) / \rho_{\mathrm{i}} L_{\mathrm{f}}$. The area of open water is given by

$$
\left[\left(1-\alpha_{\mathrm{w}}\right)\left(1-i_{\mathrm{w}}\right) F_{\mathrm{r}}+F_{\mathrm{Lw}}+F_{\mathrm{tw}}\right] A_{\mathrm{w}} \mathrm{d} t=\rho_{\mathrm{i}} L_{\mathrm{f}} H \mathrm{~d} A_{\mathrm{w}} .
$$

Combining Equations (4)-(6) and integrating yields

$$
A_{\mathrm{w}}(t)=A_{\mathrm{w} 0} C_{0} H_{*}-\left[c_{1}+c_{2} \ln \left(H_{*}\right)\right]
$$

where $\quad H_{*}=H_{0}-B t, \quad C_{0}=H_{0}\left[c_{1}+c_{2} \ln \left(H_{0}\right)\right]$, $a_{1}\left(\xi_{\mathrm{w}}+\xi_{\mathrm{L}}\right) / B, \quad c_{2}=a_{2}\left(\xi_{\mathrm{W}}+\xi_{\mathrm{L}}\right) /(2 B) \quad$ and $\left(F_{\mathrm{Lw}}+F_{\mathrm{tw}}\right) /\left(\rho L_{\mathrm{f}}\right)$.

The change in heat content of the water is a balance between gains from shortwave radiation and losses to bottom melting, i.e.

$$
\mathrm{d} Q=i_{\mathrm{w}}\left(1-\alpha_{\mathrm{w}}\right) F_{\mathrm{r}} A_{\mathrm{w}} \mathrm{d} t-F_{\mathrm{w}}\left(1-A_{\mathrm{w}}\right) \mathrm{d} t .
$$

Integrating Equation (8) between 0 and $t$ gives a solution of the form

$$
\begin{aligned}
Q(t)= & Q_{0}-(1 / B)\left\{\left[\left(1-\alpha_{\mathrm{w}}-a_{1}\right) F_{\mathrm{r}}+F_{\mathrm{w}}\right] \int\right. \\
& \left.\int A_{\mathrm{w}} \mathrm{d} H_{*}-F_{\mathrm{r}} a_{2} \int A_{\mathrm{w}} \ln (H *) \mathrm{d} H *-F_{\mathrm{w}} \int \mathrm{d} H *\right\}
\end{aligned}
$$

where $Q_{0}$ is the initial heat content at time $t=0$. If we define

$$
D_{0}=\frac{C_{0} A_{\text {wo }}}{2}\left[\frac{\pi}{C_{2}}\right]^{\frac{1}{2}}{ }_{1}\left(C_{1}-1\right)^{2} / 4 C_{2}
$$

then Equation (9) can be solved as

$$
\int A_{\mathrm{w}} \mathrm{d} H^{*}=\left.D_{0} \operatorname{erf}\left[X\left(c_{2}\right)^{\frac{1}{2}}+\left(c_{1}-1\right) / 2\left(c_{2}\right)^{\frac{1}{2}}\right]\right|_{\ln \left(H_{0}\right)} ^{\ln \left(H_{*}\right)},
$$

evaluated from $X=\ln \left(H_{0}\right)$ to $\ln \left(H_{*}\right)$, and

$$
\begin{aligned}
& \int A_{\mathrm{w}} \ln \left(H_{*}\right) \mathrm{d} H_{*}= \\
& \quad=\ln \left(H_{*}\right) \int A_{\mathrm{w}} \mathrm{d} H_{*}-D_{0}\left(Y \operatorname{erf}(Y)+\left.\left[1 /(\pi)^{\frac{1}{2}}\right) \mathrm{e}^{-Y^{2}}\right|_{Y_{1}} ^{Y_{2}}\right.
\end{aligned}
$$

TABLE I. ICE THICKNESS AND CONCENTRATION AFTER $60 \mathrm{~d}$ UNDER CENTRAL ARCTIC CONDITIONS FOR SEVERAL VARIANTS OF THE EA MODEL TOGETHER WITH THE MP, LANGLEBEN, AND ZUBOV MODELS. ENERGY FLUXES ARE IN $\mathrm{W} \mathrm{m}^{-2}$ AND ICE THICKNESS IN $\mathrm{m}$

Assumptions

\section{Model}

EA-

EA-2

$\mathrm{EA}-3$

$\mathrm{EA}-4$

MP

Langleben $\quad 0.0$

Zubov
Results evaluated from $Y_{1}=\left(c_{2}\right)^{\frac{1}{2}} \ln \left(H_{0}\right)+\left(c_{1}-1\right) /\left(2\left(c_{2}\right)^{\frac{1}{2}}\right.$ and $\left.Y_{2}=\left(c_{2}\right)^{\frac{1}{2}} \ln (H *)+c_{1}-1\right) /\left(2\left(c_{2}\right)^{\frac{1}{2}}\right.$.

Equations (5), (7), and (9) define the state of the ice-ocean system in the EA model and can be solved for any time interval desired. $F_{\mathrm{r}}, F_{\mathrm{Li}}, F_{\mathrm{Lw}}, F_{\mathrm{w}}$, and $L_{\mathrm{f}}$ are necessarily assumed to be constant during each time interval, but may be changed between intervals for improved performance. To compare the behavior of the EA model with earlier models we will use a time step of one day and ignore temporal changes in thermal forcing. Let us first examine model predictions for equilibrium ice in the central Arctic during a 60 day period at the height of the summer, assuming that $F_{\mathrm{r}}=240 \mathrm{~W} \mathrm{~m}^{-2}, \quad F_{\mathrm{Lw}}=-24 \mathrm{~W} \mathrm{~m}^{-2}, \quad F_{\mathrm{Li}}=$ $-29 \mathrm{~W} \mathrm{~m}^{-2}, F_{\mathrm{ti}}=F_{\mathrm{tw}}=0 \mathrm{~W} \mathrm{~m}^{-2}, F_{\mathrm{w}}^{\mathrm{LW}}=2 \mathrm{~W} \mathrm{~m}^{-2}, H_{0}=3 \mathrm{~m}$, $A_{\mathrm{w} 0}=0.1, \quad \alpha_{\mathrm{i}}=0.50$, and $\alpha_{\mathrm{w}}=0.1$. In addition to the standard case (EA-1), we will also look at the performance of the EA model when longwave losses and the partitioning of $F_{\mathrm{r}}$ in the ice are neglected: EA-2 includes longwave losses, but not par- titioning, EA-3 includes partitioning but not longwave losses, while EA-4 ignores both partitioning and longwave losses. Table I summarizes assumptions and final results for the various models. Figure 2 shows predicted values for $H(t), A_{\mathrm{w}}(t)$, and $Q(t)$

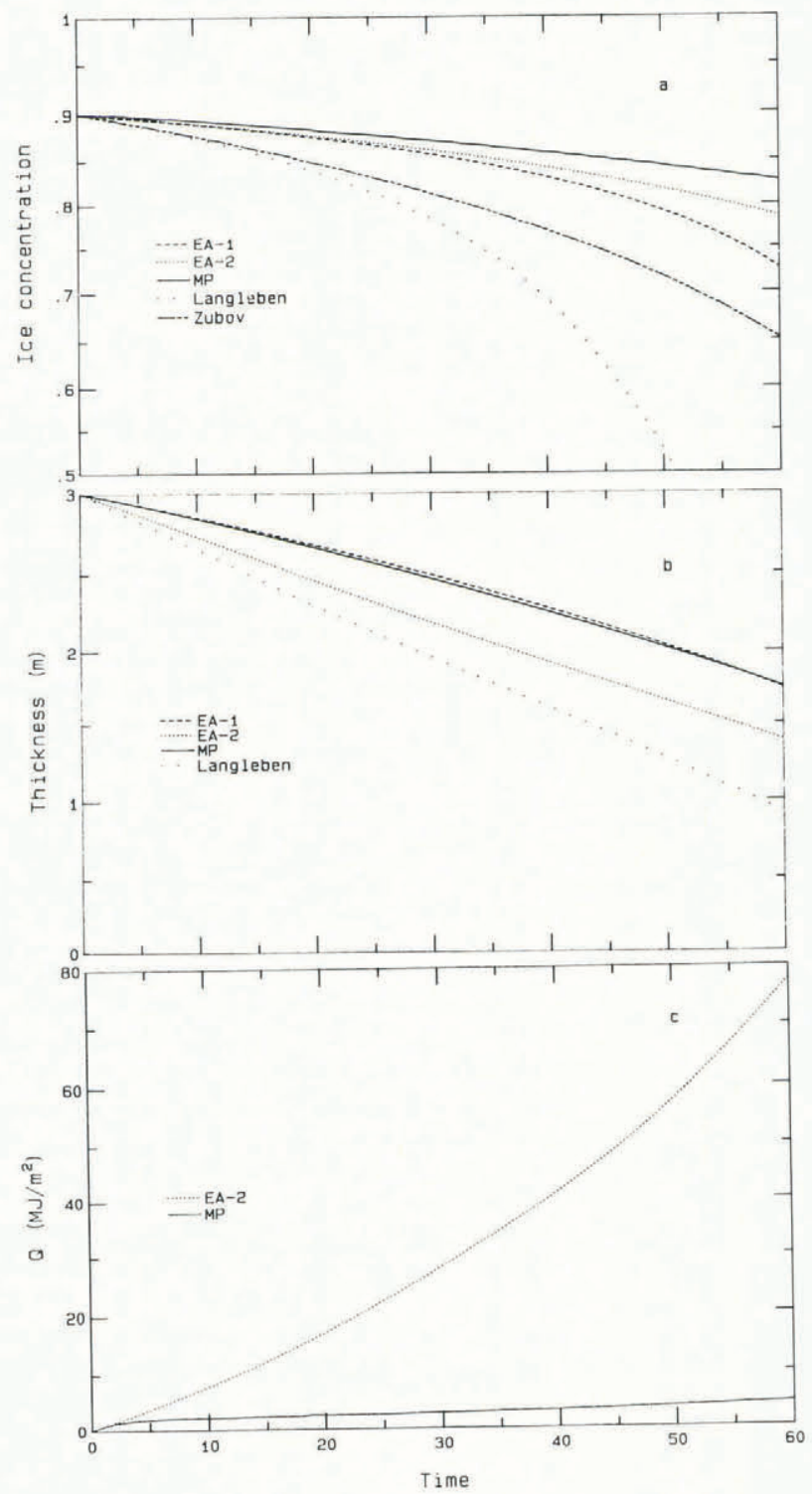

Fig. 2. Comparison of predictions made by the EA-1, EA-2, MP, Langleben, and Zubov models under Arctic conditions: (a) ice concentration, (b) ice thickness, and (c) total heat stored in the water column. Note that the Zubov model is not represented in (b) as it does not consider thinning. Since both Zubov and Langleben use all the heat absorbed in the lead for lateral melting, $Q(t)=0$ in these cases. 
Qualitatively, the temporal dependence of ice concentration is the same for all solutions, with the concentration decreasing at an increasing rate. While the Langleben and Zubov models show unrealistically large decreases in $A_{\mathrm{w}}(0.75$ and 0.25$)$, predictions by the MP and the EA-1 models are much more reasonable and are in fairly good agreement. The MP model predicts a smaller increase in $A_{\mathrm{w}}$ than any of the EA variants because it takes into account warming of the leads which results in larger heat losses to the atmosphere. The EA variants that neglect longwave radiation show very poor agreement with the MP results, particularly in the estimation of $H$. If longwave losses are ignored, the calculations suggest that estimates of ice concentration would be improved by also ignoring internal warming. This is because $\mathrm{d} A_{\mathrm{w}}$ becomes increasingly sensitive to $L_{\mathrm{f}}$ as time progresses, allowing the error in $H$ to magnify the error in $A_{\mathrm{w}}$ when $i_{0}$ is taken into account. By considering both longwave losses and ice warming, EA-1 clearly produces the best agreement in thickness; however, EA-2 produces the best agreement in concentration. Since EA-1 best represents the physics of the situation, why should neglecting ice warming yield better agreement with the MP ice concentrations? In effect two wrongs make a right in the EA-2 variant. The overestimation in $\mathrm{d} A_{\mathrm{w}}$ caused by assuming that all of $\left(1-a_{\mathrm{w}}\right)\left(1-i_{\mathrm{w}}\right) F_{\mathrm{r}}+F_{\mathrm{Lw}}$ goes to lateral melting is compensated by the underestimation which results from ignoring shortwave warming of the ice.

Inclusion of a variable $L_{\mathrm{f}}$ means that the results will change somewhat with the size of the time step. In the case of EA-1, these changes are small when $\Delta t<10 \mathrm{~d}$, but cause an increase of nearly $0.4 \mathrm{~m}$ in $H$ and 0.08 in $A_{\mathrm{w}}$ when $\Delta t=60 \mathrm{~d}$. A similar effect would have occurred had we made $F_{\mathrm{w}}$ directly dependent on $Q$. Figure 2c compares heat storage in the water column for the EA-2 and MP models. In the EA model $Q(t)$ is tied strongly to the change in ice concentration, while in the MP model the heat build-up quickly approaches an asymptotic value independent of $A_{\mathrm{w}}$. The dissimilarity between $Q(t)$ in the MP and EA models is a direct consequence of the assumptions governing $F_{\mathrm{w}}$. Neither treatment is entirely satisfactory. The MP calculations ignore the existence of the laminar sub-layer beneath the ice and are likely, therefore, to overestimate the rate of heat loss from the water column. Conversely, with a constant $F_{\mathrm{w}}$ the EA model tends to underestimate heat loss from the water column. As $Q$ increases, it is reasonable to expect a corresponding increase in $F_{\mathrm{w}}$, but at this point we do not know how rapidly $Q$ builds up or how much of $Q$ goes to $F_{\mathrm{w}}$. To determine an exact relationship between $F_{\mathrm{W}}$ and $Q(t)$, additional field observations and coupled ice-ocean models are needed.

\section{DISCUSSION}

The calculations described above were not designed to reproduce expected changes in the ice cover. Rather, we wanted to illustrate the potential importance of $i_{0}$ and $I_{\mathrm{w}}$ in determining $H$ and $A_{\mathrm{w}}$. We see that, by neglecting thinning, the Zubov approach grossly underestimates changes in $A_{\mathrm{w}}$, and the time needed to remove seasonal ice. Although the Langleben formulation appears to do a fairly good job in predicting total decay time in the near-shore region of the Arctic, temporal changes in ice thickness and concentration are unlikely to be accurate because the vertical distribution of solar energy in the ice and water is ignored. Physically, it would be difficult to divert more than a small fraction of the solar energy absorbed below the bottom of the ice to lateral melting. The EA and MP models take this into account, predicting smaller changes in $A_{\mathrm{w}}$ and enhanced thinning. The slower decrease in ice concentration weakens the positive feedback between shortwave radiation and lateral melting. The results also show that even simple simulations will suffer if longwave radiation and internal warming of the ice are ignored. The EA-1 model produces the same general ice decay characteristics as the MP model with substantially less computational complexity. In theory, time intervals of any size can be used, but accuracy will improve as the length of the interval is reduced and temporal variations in $F_{\mathrm{r}}, F_{\mathrm{w}}$, and $L_{\mathrm{f}}$ are better represented.
Even though these models contain some of the important physics, the interaction of $F_{\mathrm{r}}$ with the ice-ocean system is much more complex and care must be taken when applying them to particular regions. In areas like Fram Strait and the Southern Ocean, heat released from the warmer water underlying the mixed layer will make a major contribution to $F_{\mathrm{w}}$ which needs to be taken into account. Also potentially important is the laminar sub-layer described by McPhee and others (1987), but the longer-term implications of this layer for ice melting and heat accumulation in the mixed layer have not been investigated.

Much more difficult to deal with in a realistic way are the effects of ice motion. The unconfined Antarctic ice pack, for example experiences substantial divergence which is likely to be more important in determining $A_{\mathrm{w}}$ than is lateral melting, requiring that Equation (6) be modified to reflect expected divergence rates. Even in the Arctic Basin where the net divergence is relatively small, dynamic processes are likely to affect the way in which solar energy is transferred from the water to the ice. Theoretical studies of static leads (Maykut and Perovich, 1987) indicate that as lead width increases, the fraction of the absorbed shortwave energy contributing to lateral melting decreases. Physically, this means that much of the energy absorbed in the middle of larger leads is lost to the atmosphere before reaching the ice. Although relative motion between floes may mitigate this effect somewhat, it suggests that ice concentration, by itself, may not be sufficient to characterize the summer decay cycle.

The summer ice cover is a complex, constantly evolving mosaic of ice floes of various sizes and shapes connected by an intricate lace of open water. This complicated geometry makes it difficult to describe the distribution of open water and to directly apply results from studies of individual leads. A more tractable measure of ice-pack geometry is the floe-size distribution which undergoes a predictable shift toward floes of smaller diameter during the course of the summer melt cycle (Rothrock and Thorndike, 1984). Some preliminary attempts have been made to model this progression (Perovich, 1983), but satellite data of the type that will soon become available from active microwave sensors are needed to verify such models. As floes become smaller and more numerous, the total floe perimeter $(P)$ increases and the average distance between floes decreases. $P$ can be calculated directly from the floe-size distribution and is a measure of how much of $\left(1-\alpha_{\mathrm{w}}\right)\left(1-i_{\mathrm{w}}\right) A_{\mathrm{w}} F_{\mathrm{r}}$ actually goes to lateral melting. As $P$ becomes very large, we approach the limiting case of the EA model. Little quantitative information is presently available on the relationship between $P$ and the efficiency of lateral heat transport in the leads, but this should change in the next few years. Ultimately, we expect that parameterizations based on temporal changes in $P$ will allow us to improve our treatment of heat transport in the water significantly.

The fundamental point we have tried to make in this paper is that shortwave radiation absorbed in the upper ocean is a major factor in the seasonal decay and retreat of the ice pack which, to some degree, needs to be taken into account even in highly parameterized simulations. We have suggested ways in which some of the physics may be accommodated in relatively simple models, but it is clear that additional work is needed to accommodate dynamic effects.

\section{REFERENCES}

Andreas, E.L. and S.F. Ackley. 1982. On the differences in ablation seasons of Arctic and Antarctic sea ice. $J$. Atmos. Sci., 39(2), 440-447.

Gordon, A.L. 1981. Seasonality of Southern Ocean sea ice. J. Geophys. Res., 86(C5), 4193-4197.

Grenfell, T.C. 1979. The effects of ice thickness on the exchange of solar radiation over the polar oceans. $J$. Glaciol., 22(87), 305-320.

Grenfell, T.C. and G.A. Maykut. 1977. The optical properties of ice and snow in the Arctic Basin. J. Glaciol., 18(80), 445-463.

Langleben, M.P. 1972. The decay of an annual cover of sea ice. J. Glaciol., 11(63), 337-344.

McPhee, M.G., G.A. Maykut, and J.H. Morison. 1987. 
Dynamics and thermodynamics of the ice/upper ocean system in the marginal ice zone of the Greenland Sea. $J$. Geophys. Res., 92(C7), 7017-7031.

Maykut, G.A. and P.E. Church. 1973. Radiation climate of Barrow, Alaska, 1962-66. J. Appl. Meteorol., 12(4), 620-628.

Maykut, G.A. and D.K. Perovich. 1987. The role of shortwave radiation in the summer decay of a sea ice cover. J. Geophys. Res., 92(C7), 7032-7044.

Perovich, D.K. Unpublished. On the summer decay of a sea ice cover. (Ph.D. dissertation, University of Washington, Seattle, 1983.)

Rothrock, D.A. and A.S. Thorndike. 1984. Measuring the sea ice floe size distribution. J. Geophys. Res., 89(C4), 64776486.

Thorndike, A.S., D.A. Rothrock, G.A. Maykut, and R. Colony. 1975. The thickness distribution of sea ice. $J$. Geophys. Res., 80(33), 4501-4513.

Zubov, N.N. 1945. L'dy Arktiki [Arctic ice $]$. Moscow, Izdatel'stvo Glavsevmorputi. 